\section{Research Square}

\title{
Methylome and Transcriptome Analyses of Soybean Response to Bean Pyralid Larvae
}

\section{Wei-Ying Zeng}

Guangxi Academy of Agricultural Sciences

Yu -Rong Tan

Guangxi Academy of Agricultural Sciences

\section{Sheng-Feng Long}

Guangxi Academy of Agricultural Sciences

\section{Zu-Dong Sun ( $\nabla$ sunzudong639@163.com )}

Guangxi Academy of Agricultural Sciences

\section{Zhen-Guang Lai}

Guangxi Academy of Agricultural Sciences

\section{Shou-Zhen Yang}

Guangxi Academy of Agricultural Sciences

\section{Huai-Zhu Chen}

Guangxi Academy of Agricultural Sciences

\section{Xia-Yan Qing}

Guangxi Academy of Agricultural Sciences

\section{Research Article}

Keywords: Soybean, B ean pyralid, DNA methylation, D ifferentially methylated genes, Gene expression

Posted Date: July 27th, 2021

DOl: https://doi.org/10.21203/rs.3.rs-695343/v1

License: (c) (1) This work is licensed under a Creative Commons Attribution 4.0 International License. Read Full License

Version of Record: A version of this preprint was published at BMC Genomics on November 18th, 2021. See the published version at https://doi.org/10.1186/s12864-021-08140-w. 


\section{Methylome and transcriptome analyses of soybean response to bean}

\section{pyralid larvae}

Wei-Ying Zeng ${ }^{1}$, Yu-Rong Tan ${ }^{1}$, Sheng-Feng Long ${ }^{1}$, Zu-Dong Sun*, Zhen-Guang Lai, Shou-Zhen Yang,

Huai-Zhu Chen and Xia-Yan Qing

Wei-Ying Zeng

Email: zengweiying_1981@163.com

1 These authors contributed equally to this work

Guangxi Academy of Agricultural Sciences, Nanning, Guangxi, 530007, China

Yu-Rong Tan

Email:337662071@qq.com

1 These authors contributed equally to this work

Guangxi Academy of Agricultural Sciences, Nanning, Guangxi, 530007, China

Sheng-Feng Long

Email: 376567546@qq.com

1 These authors contributed equally to this work

Guangxi Academy of Agricultural Sciences, Nanning, Guangxi, 530007, China

Zu-Dong Sun

Email: sunzudong639@163.com

*Corresponding author

Guangxi Academy of Agricultural Sciences, Nanning, Guangxi, 530007, China

Zhen-Guang Lai

Email: 519229671@qq.com

Guangxi Academy of Agricultural Sciences, Nanning, Guangxi, 530007, China

Shou-Zhen Yang

Email: 13367811306@189.cn

Guangxi Academy of Agricultural Sciences, Nanning, Guangxi, 530007, China

Huai-Zhu Chen

Email: chhuaizhu@ sina.com

Guangxi Academy of Agricultural Sciences, Nanning, Guangxi, 530007, China

Xia-Yan Qing

Email: 717565302@qq.com

Guangxi Academy of Agricultural Sciences, Nanning, Guangxi, 530007, China 


\title{
Methylome and transcriptome analyses of soybean response to bean pyralid larvae
}

\begin{abstract}
:
Background: Bean pyralid is an important leaf-feeding insect which affects soybean production. DNA methylation can control the networks of gene expressions, and it plays an important role in the growth, development, and responses to biotic stress. However, the genome-wide DNA methylation profile of the soybean resistance to bean pyralid has not been reported so far.

Results: Using whole-genome bisulfite sequencing (WGBS) and RNA-sequencing (RNA-seq), we analysed the highly resistant material (Gantai-2-2) and highly susceptible material (Wan82-178), under the conditions of $0 \mathrm{~h}$ and $48 \mathrm{~h}$ feeding by bean pyralid larvae, to clarify the molecular mechanism of the soybean resistance and explore its insect-resistant genes. We identified 2,194, 6,872, 39,704, and 40,018 differentially methylated regions (DMRs), as well as 497, 1,594, 9,596, and 9,554 differentially methylated genes (DMGs) in the HRK0/HRK48, HSK0/HSK48, HSK0/HRK0, and HSK48/HRK48 comparisons, respectively. We found that 265 differentially expressed genes (DEGs) were negatively correlated with the DMGs, there were 34, 49, 141, and 116 negatively correlated genes in the HRK0/HRK48, HSK0/HSK48, HSK0/HRK0, and HSK48/HRK48 comparisons, respectively. The MapMan cluster analysis results indicated that negatively correlated genes in the pathways, such as protein biosynthesis and modification; primary metabolism; secondary metabolism; cell cycle, cell structure and component; RNA biosynthesis and processing, and so on. Finally, the PS-PCR and qRT-PCR were used to validate the expression patterns of several genes and the results showed an excellent agreement with deep sequencing.

Conclusions: Through the analysis of global methylation and transcription, we speculated that the expression levels of CRK40; CRK62; STK; L-type lectin-domain containing receptor kinase VIII.2; CesA; CSI1; fimbrin-1; KIN-14B; KIN-14N; KIN-4A; cytochrome P450 81E8; BEE1; ERF; SPATULA; bHLH25; bHLH79; GATA26, were regulated by methylation, and they may potentially play important roles in the soybean responses to bean pyralid larvae. Our results laid a foundation for revealing the occurrence mechanism of soybean response to bean pyralid at the level of DNA methylation.
\end{abstract}

Keywords: Soybean; Bean pyralid; DNA methylation; Differentially methylated genes; Gene expression.

\section{Background}

Bean pyralid (Lamprosema indicata (Fabricius)) is an important leaf-feeding insect in the soybean producing areas of southern China and the Huang-Huai-Hai region [1]. It can produce 4 to 5 generations a year, with overlapping of generations. When the temperatures and humidity are appropriate, bean pyralid will occur in large numbers. During the years when serious damage has occurred, only the veins and petioles are left, resulting in serious yield losses. Generally speaking, it can potentially reduce the soybean yields by $15 \%$ to $20 \%$, and by more than $30 \%$ in serious cases $[1,2]$. In view of the serious damages caused by bean pyralid, the highly resistant and highly susceptible varieties of soybean were identified [3]. The resistance of bean pyralid is inherited by two pairs of major genes plus polygenes, and the resistance loci are mainly located in linkage groups A2, C2, D1a, D1b, H, K, O [4-6]. The contents of soluble sugar, JA, CAT and PPO are related to the induction of bean pyralid larvae. Meanwhile, the contents of SOD, ET and ABA are related to the pest induction and genotypes [7]. Trypsin inhibitor A-like; chalcone isomerase 4-like; 
lipoxygenase-9; alpha-dioxygenase 1-like; lectin precursor; peroxidase 12-like; stress-induced protein SAM22; and so on, may be the potential target proteins (genes) for soybean to resist bean pyralid larvae [8-10]. In addition, such miRNAs as gma-miR156q; gma-miR166u; gma-miR166b; gma-miR319d; gma-miR394a-3p; and gma-miR396e, may also participate in the regulation of soybean resistance to bean pyralid larvae [11]. However, very little is known regarding the mechanism of epigenetic regulation related to soybean resistance to bean pyralid.

DNA methylation can turn off the activities of some genes, while demethylation can induce gene reactivity and expression. In addition, it can control the networks of gene expressions, thereby playing an important role in plant growth, development, and responses to biotic stress, and is an important means of regulating genome function [12]. Plants are often attacked by pathogens and pests during their growth and development processes. Such attacks can induce the plants to produce physiological or even gene level variations and changes in gene expressions in order to avoid or endure adversity. At the present time, the main research involves the apparent genetic effects of biotic stress on plants undergoing disease stress, such as xanthomonas oryzae pv.oryzae [13, 14]; tobacco mosaic virus [15, 16]; soybean cyst nematode [17] and Arabidopsis cyst nematode [18]. There have been few studies conducted regarding epigenetic inheritance caused by insect. As a conservative mechanism of apparent silence, the methylation of DNA affects gene expressions to a certain extent. Therefore, it can be used as an entry point to explore soybean resistance to bean pyralid.

In order to examine genome-wide DNA methylation levels during soybean resistance to bean pyralid larvae, and to determine how DNA methylation is involved in regulating the molecular mechanisms. In this study, the whole-genome bisulfite sequencing (WGBS) was performed on the leaves of Gantai-2-2 (highly resistant material) and Wan82-178 (highly susceptible material) [3] before and after exposure to bean pyralid larvae, to analyze the methylation levels of different materials and the expression patterns of related genes in the differentially methylated regions. This study provided a basis for us to explore the regulatory role of DNA methylation in soybean resistance to bean pyralid larvae. The relationship between methylation patterns and gene expression levels, as well as their role in soybean responses to bean pyralid larvae is unknown. Therefore, in order to further analyze the regulatory relationship between the differentially methylated regions and differentially expressed genes (DEGs) after soybean was subjected to insect feeding stress, we combined the genes related to the differentially methylated genes (DMGs) with the DEGs for further analysis. The genes negatively correlated with DNA methylation were screened and KEGG enrichment analysis was performed to reveal the molecular mechanism by DNA methylation mediated resistance to bean pyralid. The purpose of our study was to deepen the understanding of the regulatory relationship between DNA methylation and gene expression in soybean undergoing insect stress, and to explore the role of related genes in soybean resistance to bean pyralid larvae, so as to lay a foundation for further research regarding the molecular mechanism of soybean response to insect stress at the epigenetic level. 


\section{Results}

\section{WGBS sequence alignment and data analysis processes}

In order to study the characteristics and patterns of DNA methylation in the leaves of different resistance materials were exposed to bean pyralid larvae, we used the Illumian HiSeq4000 platform to construct DNA libraries of the highly resistant material and highly susceptible material, respectively. The materials were subjected to bean pyralid larvae feeding for $0 \mathrm{~h}$ and $48 \mathrm{~h}$. The results showed that each sample produced $40 \mathrm{G}$ filtered clean bases on average. In addition, clean reads were obtained by filtering the offline data, including the removal of any contamination, sequencing joints, and reads with high proportions of low-quality bases. The results revealed that the Q20 were $98.00 \%, 97.99 \%, 98.14 \%$, and $98.30 \%$, respectively. The conversion rates of the cytosine sites were more than $99.50 \%$ (Table 1). As detailed in Table 1, the adopted high-throughput sequencing technology method had achieved a high recognition rate. There were $89.57 \%, 89.92 \%, 92.09 \%$, and $90.50 \%$ clean reads were compared with the reference genome of soybean (https://www.ncbi.nlm.nih.gov/assembly/GCF_000004515.4) (Table 1). The comparison results indicated that DNA methylation sequencing had a high conversion rate and qualified sequencing quality.

In addition, to estimate whether or not the sequencing depth could satisfy the coverage of the sequencing data, the sequencing coverage of four DNA libraries were counted. Then, when the sequencing depth was $25 \times$, it was considered that more than $93.40 \%$ of the reading segments had been successfully covered (Table 1). Therefore, it was inferred that the overall sequencing quality of the four DNA libraries was relatively good and the vast majority of base sites had been covered.

\section{Genome-wide DNA methylation analysis process}

In order to enhance the current understanding of the epigenetic regulation and DNA methylation levels of soybean leaves with different resistance to bean pyralid larvae, we further compared the genome-wide methylation levels of the four samples. It was determined that methylated cytosine ranged from $18.37 \%$ to $21.30 \%$. Meanwhile, the average level of methylated cytosine in each context was also calculated, in the CG context ranged from $68.27 \%$ to $74.71 \%$; in the $\mathrm{CHG}$ context ranged from $42.15 \%$ to $47.64 \%$; and in the $\mathrm{CHH}$ context ranged from $4.90 \%$ to $5.81 \%$ (Table 2). It was observed that DNA methylation level in the CG context was significantly higher than that in the $\mathrm{CHG}$ and $\mathrm{CHH}$ contexts. These findings indicated that the CG context was the most important methylation context for soybean. There were found to be significant differences in DNA methylation levels among the different genotypes of materials resistant to bean pyralid larvae. For example, the DNA methylation levels of the resistant material were lower than those of the susceptible material. Also, the DNA methylation levels of the resistant material increased while those of the susceptible material decreased after the feeding stress. The increasing and decreasing results obtained in our study were found to be similar to the inconsistent variations of methylation observed in different types of rice undergoing saline-alkali stress [19].

To analyze the differences of DNA methylation patterns among various regulatory elements in 
soybean before and after feeding of bean pyralid larvae, the methylation levels of regulatory elements in different regions were examined (Table 2). There were found to be significant differences in DNA methylation levels among the different types of regulatory elements. The methylation levels of the repeat region and the $\mathrm{CpG}$-island were the highest among the different gene regions, which indicated that these two regions may be epigenetic regulatory regions which alter gene expressions. Meanwhile, the methylation levels of the mRNA were much higher than that of the exon. The average methylation levels of the $\mathrm{CG}, \mathrm{CHG}$, and $\mathrm{CHH}$ contexts in the resistant material were found to be increased among the different transcription elements. However, the opposite effects were observed in the susceptible material. The distributions of DNA methylation levels in gene region are shown in Fig.1. In the CG, CHG, and CHH contexts, the methylation levels in the upstream and downstream regions were more abundant than that in the exon region. In addition, the methylation was more frequent in the CHG context than in the CG and $\mathrm{CHH}$ contexts in the upstream, first intron, and downstream regions, which indicated that there were some tendencies and differences among the different transcription elements.

\section{Distribution ratios of the $\mathrm{mCG}, \mathrm{mCHG}$, and $\mathrm{mCHH}$ in the methylated $\mathrm{C}$-base}

The compositions of the three base types ( $\mathrm{mCG}, \mathrm{mCHG}$, and $\mathrm{mCHH}$ ) tend to vary greatly among different species and even among different samples of the same species due to in time, space, and treatments. Therefore, in order to further analyze the distributions of the different methylated sites, all of the methylated $\mathrm{C}$ sites were selected and recombined (Table 3). After bean pyralid larvae feeding for $48 \mathrm{~h}, \mathrm{mCG}$ in the resistant material decreased from $36.16 \%$ to $34.47 \%$, mCHG decreased from $34.42 \%$ to $32.80 \%$, and $\mathrm{mCHH}$ increased from $29.42 \%$ to $32.73 \%$. $\mathrm{mCG}$ in the susceptible material decreased from $36.20 \%$ to $34.78 \%$, mCHG decreased from $34.22 \%$ to $32.86 \%$, and $\mathrm{mCHH}$ increased from $29.58 \%$ to $32.39 \%$. The methylation levels of $\mathrm{mCG}$, $\mathrm{mCHG}$, and $\mathrm{mCHH}$ in the resistant and susceptible materials were similar before and after bean pyralid larvae feeding. Therefore, the results indicated that the genotype had little effect on the methylation levels of the $\mathrm{mCG}, \mathrm{mCHG}$, and $\mathrm{mCHH}$, and the methylation levels were mainly affected by the insect stress.

The methylation levels of each type of methylated $\mathrm{C}$ were statistically analyzed (Fig.2). The analysis results revealed that when the methylation levels ranged from $0 \%$ to $60 \%$, the distribution proportions of the methylated $\mathrm{C}$ followed the order of $\mathrm{mCHH}>\mathrm{mCHG}>\mathrm{mCG}$. However, when the methylation levels were between $60 \%$ and $80 \%$, the distribution proportions followed the order of $\mathrm{mCHG}>\mathrm{mCHH}>\mathrm{mCG}$. Furthermore, when the methylation levels were higher than $80 \%$, the $\mathrm{mCG}$ site were found to be significantly increased.

\section{Identification of the differentially methylated genes}

By comparing the methylation levels of the different samples, we were able to successfully identify the differentially methylated region (DMR) (FDR $<0.05)$. The number of DMRs identified in the HRK0/HRK48 in the CG, CHG, and CHH contexts were 664, 1,550, and 0, respectively; in 
the HSK0/HSK48 were 2,200, 4,670, and 2, respectively; in the HSK0/HRK0 were 19,200, 20,272, and 31, respectively; and in the HSK48/HRK48 were 19,178、20,807, and 33, respectively. Also, DMRs detected at the CG and CHG contexts were found to be significantly higher than that at the $\mathrm{CHH}$ context.

According to the accepted definition, the genes in the DMR region and the specific gene functional elements which overlap no less than $1 \mathrm{bp}$ are the DMGs/DMR-associated promoters (DMPs). A total of 497 no-repeated DMGs (207 hyper-DMGs and 290 hypo-DMGs) and 223 no-repeated DMPs (99 hyper-DMPs and 124 hypo-DMPs) were identified in the HRK0/HRK48, of which 48 DMGs appeared in both promoter and gene body regions, simultaneously. In the HSK0/HSK48, 1,594 no-repeated DMGs (687 hyper-DMGs, 882 hypo-DMGs and 25 shared-DMGs) and 612 no-repeated DMPs (235 hyper-DMPs and 377 hypo-DMPs) were identified, of which 186 DMGs appeared in both promoter and gene body regions, simultaneously. In the HSK0/HRK0, 9,596 no-repeated DMGs (2,717 hyper-DMGs, 6,577 hypo-DMGs and 302 shared-DMGs) and 3,173 no-repeated DMPs (1,357 hyper-DMPs, 1,786 hypo-DMPs and 30shared-DMPs) were identified, of which 1,479 DMGs appeared in both promoter and gene body regions, simultaneously. In the HSK48/HRK48, 9,554 no-repeated DMGs (2,944 hyper-DMGs, 6,302 hypo-DMGs and 308 shared-DMGs) and 3,217 no-repeated DMPs (1,542 hyper-DMPs, 1,636 hypo-DMPs and 39 shared-DMPs) were identified, of which 1,379 DMGs appeared in both promoter and gene body regions, simultaneously. The statistical analysis showed that the number of hyher-DMGs were fewer than the hypo-DMGs after bean pyralid larvae feeding. Therefore, it was confirmed that the decreases of genome-wide DNA methylation levels may be one of the causes of the responses of plants to insect stress.

\section{Gene ontology (GO) annotation and Kyoto encyclopedia of genes and genomes (KEGG) pathway enrichment analyses of the DMGs}

To better understand the functions of DMGs, Go annotation analysis was conducted. The DMGs in the four comparisons were involved in the biological process, cellular component and molecular function. During the biological process, the DMGs were mainly enriched in cellular process, metabolic process, biological regulation, regulation of biological process, response to stimulus, and so on. In the cellular component, the DMGs were mainly concentrated in the cell, cell part, membrane, membrane part, organelle, and other components. In the molecular function, the DMGs were mainly involved in binding and catalytic activity. It was speculated that the methylation patterns of the different contexts among the four comparisons were consistent in subcellular localization, molecular function, and biological process.

In order to further identify the metabolic pathways and functions of the DMGs, the obtained DMGs were compared in the KEGG database (Table 4). It was found that a total of 151 DMGs at the CG context in the HRK0/HRK48 had participated in 71 pathways, with one pathway being significantly enriched; 259 DMGs at the CHG context had participated in 80 pathways, with one pathway being significantly enriched. In the HSK0/HSK48, 671 DMGs at the CG context had 
participated in 108 pathways, with 8 pathways being significantly enriched; 667 DMGs at the CHG context had participated in 103 pathways, with 3 pathways being significantly enriched. In the HSK0/HRK0, 6,923 DMGs at the CG context had participated in 132 pathways, with 5 pathways being significantly enriched; 1,907 DMGs at the CHG context had participated in 134 pathways, with 11 pathways being significantly enriched. In the HSK48/HRK48, 6,851 DMGs at the CG context had participated in 134 pathways, with 11 pathways being significantly enriched; 1,943 DMGs at the CHG context had participated in 125 pathways, with 2 pathways being significantly enriched. Therefore, it was speculated that the methylation of the different contexts may have had a tendency to participate in the regulation of the biological functions. These pathways provided a useful reference for studying the biological processes and functions of the genes.

\section{Interconnection of DMGs and DEGs}

The goal was to further the current understanding of the relationships between transcriptome and methylation of soybean resistance to bean pyralid larvae, thus the data from WGBS and RNA-Seq [10] were jointly analyzed. The correlation analysis results showed that (Fig. 3), a total of 512 common genes were obtained from the four comparisons, of which 265 genes showed negative regulation (Table S1), and 247 genes showed positive correlations. In the HRK0/HRK48, 64 DEGs were determined to be associated with the DMGs, including 34 negatively correlated genes, of which 11 negatively correlated genes were occurred in the promoter region. In the HSK0/HSK48, 93 DEGs were determined to be associated with the DMGs, including 49 negatively correlated genes, of which 10 negatively correlated genes were occurred in the promoter region. In the HSK0/HRK0, 236 DEGs were determined to be associated with the DMGs, including 141 negatively correlated genes, of which 98 negatively correlated genes were occurred in the promoter region. In the HSK48/HRK48, 194 DEGs were determined to be associated with the DMGs, including 116 negatively correlated genes, of which 84 negatively correlated genes were occurred in the promoter region. Therefore, it was speculated that the changes in DNA methylation levels of the 265 negatively correlated genes may be one of the reasons for the significant differences in the gene transcription levels induced by bean pyralid larvae feeding. Meanwhile, the changes in DNA methylation levels of the 247 positive correlated genes may not have been the reason for the direct regulation of the gene transcription levels. Subsequently, we will focus on the 265 negatively correlated genes, which are considered to be of significance of the biological processes in plant responses to insect stimulus, whether for in-depth explorations of gene functions or pattern analyses of DNA methylation.

\section{KEGG enrichment analysis of negatively correlated genes}

The results showed that 10 negatively correlated genes $(29.41 \%)$ in the HRK0/HRK48 were enriched in 11 pathways (Table S2), among those, 4 pathways were found to be significantly enriched, including RNA transport, ascorbate and aldarate metabolism, fatty acid biosynthesis, and porphyrin and chlorophyll metabolism. In the HSK0/HSK48, 13 negatively correlated genes 
(26.53\%) were enriched in 23 pathways (Table S2), among those, 5 pathways were found to be significantly enriched, including ubiquinone and other terpenoid-quinone biosynthesis, sulfur relay system, thiamine metabolism, selenocompound metabolism, ether lipid metabolism. In the HSK0/HRK0, 56 negatively correlated genes (39.72\%) were enriched in 65 pathways (Table S2), among those, 6 pathways were found to be significantly enriched, including pyruvate metabolism, propanoate metabolism, glyoxylate and dicarboxylate metabolism, carbon metabolism, lipoic acid metabolism, carotenoid biosynthesis. In the HSK48/HRK48, 72 negatively correlated genes $(62.07 \%)$ were enriched in 58 pathways (Table S2), among those, 5 pathways were found to be significantly enriched, including carbon metabolism, propanoate metabolism, lipoic acid metabolism, pyruvate metabolism, biosynthesis of amino acids. The results suggested that various defense responses in the plants would be activated when the soybean were subjected to feeding stress caused by bean pyralid larvae.

In addition, KEGG enrichment analysis of negatively correlated genes in the promoter regions showed that, in the HRK0/HRK48, two negatively correlated genes (18.18\%) with DMRs located in the promoter regions were enriched in 4 pathways (Table S3). In the HSK0/HSK48, 5 negatively correlated genes $(50.00 \%)$ with DMRs located in the promoter regions were enriched in 10 pathways (Table S3), among those, 2 pathways were found to be significantly enriched, including monoterpenoid biosynthesis, and SNARE interactions in vesicular transport. In the HSK0/HRK0, 30 negatively correlated genes (30.61\%) with DMRs located in the promoter regions were enriched in 42 pathways (Table S3), among those, 5 pathways were found to be significantly enriched, including endocytosis, glycolysis/gluconeogenesis, pyruvate metabolism, RNA degradation, sesquiterpenoid and triterpenoid biosynthesis. In the HSK48/HRK48, 31 negatively correlated genes (36.90\%) with DMRs located in the promoter regions were enriched in 40 pathways (Table S3), among those, 3 pathways were found to be significantly enriched, including endocytosis, monoterpenoid biosynthesis, sesquiterpenoid and triterpenoid biosynthesis.

\section{Functional analysis of the negatively correlated genes}

For further understanding the resistance mechanism of the soybean to bean pyralid larvae, Mercator software was used to obtain the classification statistics of 265 negatively correlated genes, of which 114 were annotated into 24 categories (Table S4). These genes were determined to be mainly related to such pathways as protein biosynthesis and modifications; primary metabolism; secondary metabolism; cell cycles, cell structures and components; phytohormone actions; external stimuli responses, and so on. The results indicated that the DEGs regulated by the methylation were involved in many biological pathways after bean pyralid larvae feeding.

Proteins cannot only be used as defensive compounds, but also as primary nitrogen sources. Thereby, they play an important role in plants' resistance to biotic stress [20]. A total of 31 DEGs related to protein metabolism and modification (Table S4). Ribosome is also known as an intracellular protein synthesis factory. Five DEGs related to ribosome biosynthesis were identified, for example, two genes were up-regulated in the HRK0/HRK48; one gene was up-regulated in the 
HSK0/HSK48; one gene was up-regulated in the HSK0/HRK0 and HSK48/HRK48; one gene was down-regulated in the HSK0/HRK0 and HSK48/HRK48. It is speculated that the expressions of ribosomes in the soybean's leaves increased after bean pyralid larvae feeding, thereby increasing synthesis of protein and thus resisting the insect pests. Plant E3 ubiquitin ligase is a key enzyme in the ubiquitin proteasome pathway, and plays an important role in regulating hormone response, participating in morphogenesis, disease defense response, and abiotic stress response [21]. We identified 4 ubiquitin-fold protein conjugation related genes, including three genes related to E3 ubiquitin-ligase activities, among them, one gene was up-regulated in the HSK0/HRK0 and HSK48/HRK48; one gene was up-regulated in the HSK0/HSK48; one gene was down-regulated in the HSK48/HRK48; one gene was down-regulated in the HSK0/HSK48. Therefore, it was speculated that the genes related to ubiquitin-fold protein conjugation were involved in the physiological and biochemical processes of soybean cells during the process of insect stress, in order to ensure the metabolic levels of soybean cells and maintain the ubiquitination processes. Protein kinases are involved in plant signaling pathways [22]. We identified 13 DEGs related to protein kinases, among which three genes were down-regulated in the HSK0/HSK48; three genes were up-regulated in the HSK0/HRK0 and HSK48/HRK48; two genes were down-regulated in the HSK0/HRK0 and HSK48/HRK48; one gene was up-regulated in the HSK0/HRK0; one gene was up-regulated in the HSK48/HRK48; two genes were down-regulated in the HSK48/HRK48; one gene was up-regulated in the HRK0/HRK48 and HSK0/HSK48. Our results suggested that the expression levels of protein kinase can be changed by bean pyralid larvae feeding, and the genes related to protein kinase play important roles in the defense response of soybean against bean pyralid larvae. Translation initiation factor family genes are the keys to translation initiation in eukaryotes, and also play a regulatory role in cell development and growth [23]. We identified two genes related to translation initiation. Among them, one gene was up-regulated in the HSK0/HRK0; one gene was up-regulated in the HSK0/HSK48. As the second largest member of the serine protease family, subtilisin-like protease (SBT) is a type of protein induced and expressed by stress in plants, whose main functions involved in development regulation and signal transduction protein degradation [24]. We identified that the SBT2 was up-regulated in the HSK0/HRK0. Three genes related to protein hydrolysis were also identified, among them, one gene was down-regulated in the HSK0/HRK0; one gene was up-regulated in the HRK0/HRK48; one gene was up-regulated in the HSK0/HRK0 and HSK48/HRK48. And two genes related to organelle machinery, among them, one gene was down-regulated in the HSK0/HSK48; one gene was up-regulated in the HSK0/HSK48. These results indicated that the protein synthesis and secretion were significantly altered after bean pyralid larvae feeding. Therefore, it was concluded that protein metabolism and protein modification play important roles in the plant immunity levels induced by insect pests.

The activation and production of insect-resistant substance metabolism in plants usually consume a certain amount of growth energy. When the anti-insect defense mechanism of plants is 
activated, it will also lead to some changes and recombination in the morphology and primary metabolism of the affected plants [25]. We identified 26 DMGs related to cell cycle, cell structure, and cell component. Among them, 12 genes related to cell cycle organization, of which six genes were up-regulated in the HSK0/HRK0; three genes were up-regulated in the HRK0/HRK48; one gene was down-regulated in the HSK0/HRK0; one gene was down-regulated in the HSK48/HRK48; one gene was up-regulated in the HSK0/HSK48. Most of the genes related to cell cycle were found to be up-regulated, which displayed enhanced cell proliferation. These genes then participated in the regulation of soybean resistance to bean pyralid larvae. There were 8 DEGs related to cell wall organization, among them, three genes were up-regulated in the HSK0/HRK0; three genes were up-regulated in the HSK0/HSK48; one gene was up-regulated in the HSK0/HRK0 and HSK48/HRK48; one gene was up-regulated in the HSK48/HRK48. There were five DEGs related to cytoskeleton organization, among them, two genes were up-regulated in the HRK0/HRK48; two genes were up-regulated in the HSK0/HSK48; one gene was up-regulated in the HSK0/HRK0. One gene identified was related to chromatin organization, such as ARP7 was up-regulated in the HSK48/HRK48. The expression levels of those genes were all up-regulated after bean pyralid larvae feeding. This up-regulation may assist in the plant cell wall structuring processes in order to create a stronger physical protective layer against insects and reduce the damages to soybean undergoing insect stress. Primary metabolites are considered to be important intermediate products of plant growth, and are easily digested and absorbed by insects [20]. It was found that some of the genes related to primary metabolism, such as carbon metabolism, lipid metabolism, amino acid metabolism, coenzyme metabolism, were also affected by bean pyralid larvae. A total of six DEGs related to lipid metabolism; two DEGs related to amino acid metabolism; three DEGs related to carbon metabolism; and five DEGs related to coenzyme metabolism were identified. Among them, three genes were up-regulated in the HSK0/HRK0; one gene was down-regulated in the HSK0/HRK0; two gene were up-regulated in the HSK48/HRK48; two genes were down-regulated in the HSK48/HRK48; two genes were down-regulated in the HSK0/HSK48; three genes were up-regulated in the HSK0/HSK48; one gene was up-regulated in the HRK0/HRK48; one gene was down-regulated in the HSK0/HRK0 and HSK48/HRK48; and one gene was up-regulated in the HSK0/HRK0 and HSK48/HRK48. The differences of primary metabolic response between resistant and susceptible materials indicated that they had different abilities regarding replenishing pest damage losses, which was considered to be beneficial to the restriction of soybean undergoing insect nutrient intake conditions.

Secondary metabolites are also known to play an important role in plant defense against phytophagous insects. Flavonoids are a class of secondary metabolites widely existing in plants, which provide essential substances for plant growth, reproduction, and survival, as well as enhancing plant resistance to insects, and disease [26]. Two DEGs related to flavonoid biosynthesis were identified. Among them, cytochrome P450 81E8 (related to terpenoid) was up-regulated in the HSK48/HRK48. These findings indicated that insect pests could potentially 
induce the synthesis of terpenoid in insect resistant soybean leaves.

Transcription factors are also known to play an important regulatory role in plant biotic and abiotic stresses responses by activating or shutting down plant immune defense systems [27]. GATA26 was up-regulated in the HSK48/HRK48; BEE1, ERF and SPATULA were up-regulated in the HSK0/HRK0; putative Myb family transcription factor At1g14600 was down-regulated in the HRK0/HRK48; bHLH79 was up-regulated in the HSK0/HSK48. These transcription factors were considered to be one of the important factors in the plant responses to insect feeding damages.

As signaling molecules, plant hormones play a role in regulating plant growth and development, as well as participating in the regulation of plant responses to various biotic and abiotic stresses, and they are the most direct physiological responses to insect damage effects [28]. For example, protein PIN-LIKES 3 (auxin efflux transporter) was up-regulated in the HSK0/HRK0. It is speculated that the high expressions of this gene in the resistant material may have affected the synthesis of auxin in the leaves, which had broken the hormone balance in the plants, resulting in the emergence of insect resistance in Gantai-2-2. Receptor-like protein kinase FERONIA-like (related to signalling peptides) was down-regulated in the HSK0/HRK0 and HSK48/HRK48. When comparing the resistant and susceptible materials, there were two DEGs related to phytohormone actions were observed (one up-regulated and one down-regulated). This may have been the reason why soybean itself had changed from a growth mode to a defense mode, indicating that there was a potential trade-off between growth and defense. However, since both processes require high metabolism, they cannot be carried out at a high level at the same time [29].

\section{Validation analysis of negatively correlated genes}

In order to further verify that the negative correlations between DNA methylation and the transcriptome were not random, five negatively correlated genes were randomly selected. PS-PCR and qRT-PCR technologies were used to analyze their DNA methylation patterns and gene expression patterns. The results revealed that the PS-PCR expressed patterns and WGBS sequencing expressed patterns of five DMRs were all the same. Moreover, all of the qRT-PCR expression patterns of the five DEGs were consistent with the RNA-Seq expression patterns (Fig. 4). These findings indicated that the sequencing results of WGBS and RNA-Seq were reliable, and that the DNA methylation may regulate the responses of soybean to pest stress by regulating the expression levels of genes related to insect resistance.

\section{Discussion}

\section{Genome-wide DNA methylation characteristics of soybean resistance to bean pyralid larvae}

Since DNA methylation may potentially participate in the regulations of gene expressions, as well as the maintenance of genome stability, gene silencing in plants, it thereby plays important regulatory roles in plant growth, development, and stress resistance [19, 30, 31]. We found that the 
genome-wide DNA methylation levels of the four samples ranged from $18.37 \%$ to $21.30 \%$, the results consistent with the plant genome-wide DNA methylation levels ranged from $6.00 \%$ to $30.00 \%$ [32, 33]. DNA methylation was found in the CG, CHG, and CHH contexts in plants, and different methylation contexts have different modification patterns [32, 33]. We also found that genome-wide DNA methylation of the four samples occurred in different degrees in the CG, CHG, and $\mathrm{CHH}$ contexts. This was particularly evident since the methylation levels in the CG context were significantly higher than that in the $\mathrm{CHG}$ and $\mathrm{CHH}$ contexts, which suggested that the $\mathrm{CG}$ context was the most important methylation context in soybean. These results were consistent with the type and level of DNA methylation detected in different tissue parts of soybean [34, 35]. In addition, these findings indicated that the differences of DNA methylation in all patterns may have played important roles in the soybean responses to insect stress.

Expression analysis of the important genes related to soybean resistance to bean pyralid larvae

When plants are attacked by herbivorous insects, they activate a series of molecular signals in order to start their biotic defense responses [36]. By combining KEGG pathway and MapMan enrichment analysis, we found that some defense-related candidate genes had different methylation and transcription reactions after bean pyralid larvae feeding.

Cysteine-rich receptor-like protein kinase (CRK) is one of the largest families of receptor-like protein kinase (RLK) in plants. As an important molecule in both biotic and abiotic stress signaling pathways, it was involved in the regulation of plant immune responses [37]. There were determined to be $76 \mathrm{CRK}$ promoter regions in soybean which contained biotic stress response elements, suggesting that CRK plays an important role in biotic stress [38]. LRR-receptor-like kinase is the largest family of receptor protein kinases in plants, and plays an important regulatory role in plant growth, development, biotic and abiotic stresses [39]. Serine/threonine protein kinase (STK) is an important signaling molecule. When plants are exposed to stress, such as insect feeding, salt damage, drought, and so on, STK is rapidly activated by phosphorylation as serine and threonine residue. This further activates downstream signaling molecules through cascade phosphorylation for the purpose of activating specific signal transduction pathways, and finally transmits external signals to the nuclei in order to activate or inhibit the expressions of specific genes [39-41]. It has been determined that insect feeding stress can induce STK expressions in arabidopsis [42] and soybean [43]. The MAPK signaling pathway is an important downstream component of the calcium signaling pathways [44], and is also a member of the serine/threonine protein kinase family [45]. It was also related to plant insect induced defense responses, such as MAPK signaling pathway was activated after tobacco was fed by insects [46]. NaMEK1, NaMEK2, NaMKK1, NaSIPKK, and NaNPK2 in Nicotiana attenuata play important roles in the plants' defense against Manduca sexta. These five MAPKKs have the ability to regulate the levels of trypsin inhibitors, thereby inhibiting trypsin activities and resisting damages caused by herbivorous insects [47, 48]. AtMKK3 in arabidopsis can inhibit the growth of Spodoptera 
littoralis [49]. Lectin-like receptor kinases (LecRLKs), as a major subfamily of plant receptor-like protein kinases, play an important role in plant pest resistance, as they can combine with exogenous glycosyl to protect plants from herbivores or phytophagous invertebrates [50-52]. For example, LecRK1 in Nicotiana attenuata plays an important role in plant defense responses triggered by Manduca sexta [53, 54]. In addition, the resistance of brown planthopper (BPH) was enhanced after over-expression of $O s L e c R K$, but decreased significantly after the gene silence in rice [55]. The results obtained that 11 DEGs related to protein kinase, such as CRK40; CRK62; probable LRR receptor-like serine/threonine-protein kinase At1g53430; STK; MAP3K-WNK; MAP4K; L-type lectin-domain containing receptor kinase VIII.2, and so on, were identified. These results indicated that plant protein kinases, as receptors of the signaling molecules, had the ability to sense external stimuli. It was speculated that plant protein kinases, as important signaling molecules, are involved in soybean resistance to insect stress and play very important regulatory roles in soybean resistance to bean pyralid larvae.

Plant cell walls are the primary cell structures sensing external stress signals, and are involved in maintaining cell morphology and related to such physiological activities as extracellular signal recognition. They are essentially the first line of defense against pathogens or insect pests [56,57]. Therefore, changes in the composition and structures of cell walls play a very important role in plant growth and development, as well as external stress responses [58]. Cellulose synthase complex (CSC) is the main site for the synthesis of cellulose in plant cell walls [59]. CSC is assembled by cellulose synthase monomer (CesA) on the Golgi complex, and is transported by secretory vesicles and bound to cell membranes $[60,61]$. Therefore, the transcription of CesA, along with the assembly and transportation of CSC complex, are of major significance to the regulation of cellulose biosynthesis. Plant cells can regulate cell wall formation through CSC assembly and transportation, thereby participating in plant morphogenesis and stress responses [61, 62]. It was observed that following IAA treatments of cotton, GhCesAl and GhCesA2 were significantly up-regulated [63]. CSI1 is known to be involved in the formation of SmaCC/MASC and participates in the rapid recovery of CSC in plasma membrane after the stress conditions have subsided [64, 65]. Moreover, CSI1 directly mediates the interactions between CSCs and microtubules. In the absence of CSI1, the arrangements of CSCs and microtubules will be disrupted [66]. Fimbrin is a class of microfilament cross-linked proteins with conserved amino acid sequences. As a microfilament binding protein, fimbrin is one of the important regulatory factors of microfilament skeletons [67]. Kinesin (KIN) uses the energy produced by its hydrolysis of ATP to move along microtubules and provide power for intracellular material transport. For example, FRA1 of the arabidopsis KIN-4 family is a driver protein which moves to the positive ends of microtubules, and its function deficient mutant FRA1 showed irregular depositions of cellulose microfibrils on cell walls, making the stem brittle [68-70]. CLASP can be used as a regulatory protein of microtubule binding proteins $[71,72]$. We found that a considerable number of genes related to the cell wall and cell cycle metabolism pathways were changed, such as CesA, 
CSI1, fimbrin-1, KIN-14B, KIN-14N, KIN-4A, CLASP, and so on. Therefore, it was considered that those genes may assist in soybean cell structuring processes to create stronger physical protective layers against insects and maintain the stability of the cells and organelles. When soybean is stressed by insects, the anti-insect signaling pathways are activated after sensing cell wall damage, which activates a series of cell defense responses. As a result, the resistance of soybean becomes greatly enhanced. Moreover, the genes related to cell cycle can also effectively regulate plant tolerance to insects [73].

Cytochrome P450 (CYP) is a class of plant antioxidant inducers and detoxification genes, which have the ability to catalyze a number of substances which have defense functions in organisms, such as sterols, isoflavones, alkaloids, and terpenes, and plays an important role in the defense of organisms from diseases, and insects stress [74-76]. The cyanogen glycosides synthesized by CYP79A and CYP71E1 in sorghum were toxic to pests [77]. In addition, the expression of CYP71Al was induced after BPH feeding in rice [78]. We found that the expression of cytochrome P450 81E8 in the resistant material was higher than that in the susceptible material after bean pyralid larvae feeding. These findings indicated that insect feeding stress could induce the release of terpenoids from the resistant material. Therefore, it was speculated that soybean will use the cytochrome P450 family to reduce the threats caused by pests.

Transcription factors are important regulators which control the expression levels of all biological genes. They can regulate the expressions of multiple genes related to biotic stress, improve plant resistance to disease and insects, and play important roles in plant development and stress responses [28, 79]. In plant induced defense processes, insect invasions activate the AP2/ERFs family proteins through signal transduction pathways in order to activate downstream gene expressions which regulate stress responses [80]. ERF is a major subfamily of the AP2/ERF transcription factor family, and also plays an important regulatory role in plant resistance to diseases and pests [81]. For example, the combination of SSaERF1 and GCC-box can enhance the resistance of arabidopsis to Prodenia litura [82], and BrERF11b has the ability to enhance the resistance of tobacco to Myzus persicae and Prodenia litura [83], thus indicating that plant resistance to insect stress can be improved through the over-expression of ERF. In addition, bHLH are the second largest class of transcription factors in plants, and play an important role in plant growth and development, physiological metabolism, and stress response [84]. BEE1 belong to bHLH family and are important elements in regulating brassinolide signal transduction [85]. Also, GATA is a member of the zinc finger protein family, and plays an important role in plant resistance to biotic and abiotic stresses [86]. The expression levels of BEE1, ERF, and SPATULA in the resistant material were found to be higher than those in the susceptible material before soybean were stressed by bean pyralid larvae, which indicated that these three transcription factors were related to the genotypes of the resistant materials. It was determined that bHLH25 and GATA 26 were induced to express in the resistant materials, and bHLH79 was induced to express in the susceptible materials. Therefore, it was speculated that the differentially expressions of 
these transcription factors may be important reasons for the differences in the induced resistance levels and the persistence of resistant and susceptible soybean varieties.

\section{Conclusions}

In order to further understand the molecular mechanism of soybean responses to bean pyralid larvae, we used WGBS to analyze the genome-wide methylation of highly resistant and highly susceptible soybean leaves before and after bean pyralid larvae feeding. It was found that DNA methylation levels of specific genes changed in response to insect stress. According to the DNA methylation and transcriptome association analysis, we concluded that there was a mainly negative correlation between DNA methylation and gene expression to a certain extent. And the response to bean pyralid might be related to the pathways, such as protein biosynthesis and modification; primary and secondary metabolisms; cell cycle, cell structure and component; phytohormone action; RNA biosynthesis and processing, and so on. At the same time, by analyzing the expression levels and methylation patterns of those genes, the relationships between their methylation status and expression levels in different materials were revealed, and the roles of these related genes in the induction processes could be explored. This research investigation comprehensively analyzed the molecular mechanism of soybean undergoing insect stress from the two aspects of transcription levels and methylation levels, which was of great significance to the research of soybean insect resistance.

\section{Materials and method}

\section{Experimental materials}

Both the highly resistant material (Gantai-2-2) and highly susceptible material (Wan 82-178) were planted in gray insect-proof net rooms on a test field at the Guangxi academy of agricultural sciences in the summer of 2019. When the plant growth reached 10 compound leaves, the fourth instar larvae of bean pyralid were grafted to each seedling according to a density of five larvae. Samples were taken at $0 \mathrm{~h}$ and $48 \mathrm{~h}$ after grafting. The samples were quickly frozen in liquid nitrogen and stored at $-80^{\circ} \mathrm{C}$ for further use.

\section{Total DNA extraction and detection}

Total genomic DNA was extracted from soybean leaves using a DNeasy Plant Mini Kit (Qiagen, Valencia, CA, USA). The degradation of DNA in the samples was detected by agarose gel electrophoresis. The OD260/280 values of DNA were detected using a Nano Drop 2000 spectrophotometer (Thermo Fisher Scientific, MA, USA), and the concentration levels of DNA were accurately quantified by Qubit. The qualified DNA samples were used for the library construction.

\section{Sequencing analysis of the bisulfite}

For WGBS library constructing, the DNA was broken into fragments with a mean size of $250 \mathrm{bp}$ using Bioruptor (Diagenode, Belgium). Following end repair and adenylation, the sonicated DNA 
fragments were ligated to cytosine-methylated barcodes according to manufacturer's instruction. EZ DNA Methylation-Gold kit (Zymo research, CA, USA) was used for bisulfite treatments. Different Insert size fragments were excised from the same lane of a 2\% TAE agarose gel. Products were purified by using a QIAquick Gel Extraction kit (Qiagen, Valencia, CA, USA) and amplified by PCR. Finally, the qualified DNA library was sequenced on an Illumina Hiseq4000 platform with Hiseq paired-end reads by Shenzhen Huada Gene Research Institute (Shenzhen, China, BGI).

\section{Data filtering and sequence alignment}

The raw data were filtered by removing adapter sequences, contamination and low-quality sequences. After the filtering process was completed, BSMAP software was used to compare the clean reads with the soybean reference genome, and the comparison rates and bisulfite conversion rates were calculated. In order to calculate the methylation levels of each site, we calculated the proportion of the number of reads supporting methylation to the total number of reads covering the site [87]. The formula was as follows: $R m_{\text {average }}=\frac{N m_{a 11}}{N m_{\text {all }}+N n_{\text {mall }}} * 100 \%$

$\mathrm{Nm}$ represents the reads number of $\mathrm{mC}$, while $\mathrm{Nn}$ represents the reads number of non-methylation reads.

\section{DMR detection}

A window containing at least five $\mathrm{CG}(\mathrm{CHG}$ or $\mathrm{CHH})$ was found at the same position in two of the sample genomes, and the differences in the CG methylation levels between the two samples of that window were compared. The region with significant differences (Fisher's Exact, 2-fold change, and $p$-value $\leq 0.05$ ) in the methylation between the two samples was referred to as DMR. If the contiguous region formed by the two adjacent DMRs differed significantly in methylation levels in the two samples, the two DMRs were combined into a single contiguous DMR. Otherwise, they were considered to be two independent DMRs.

\section{Differences in methylation levels}

CIRCOS software was used to compare the differences in the methylation levels of the DMR between the samples in order calculate the differences in the methylation levels samples. The formula was as follows: $\operatorname{deg}$ ree of difference $=\frac{\log _{2} R m 1}{\log _{2} R m 2}$

Where $R m 1$ and $R m 2$ represent the methylation levels of $\mathrm{mC}$ for sample 1 and sample 2, respectively. If the value of $R m 1$ or $R m 2$ is 0 , it shall be replaced by 0.001 [88].

\section{Bioinformatic analysis process}

Gene Ontology (GO) enrichment analysis method was used to provide all the GO terms which were significantly enriched in the DMGs, and to filter the DMGs with specific biological functions. Based on the GO TermFinder (http://www.yeastgenome.org/help/analyze/go-term-finder), the number of genes in each term was 
calculated. Then, a hypergeometric test method was used to find the GO terms which were significantly enriched in the DMGs when compared with the whole genome background. The GO terms with a $p$-value $\leq 0.05$ were regarded as significantly enriched.

KEGG is the main public database for those pathways [89]. Through significant enrichment analyses of the pathways, it can be determined which pathways are significantly enriched in the DMGs when compared with the whole genome background, taking the KEGG pathway as a unit. Pathways with a $p$-value $\leq 0.05$ were regarded as significantly enriched.

\section{Conjoint analysis of genome-wide DNA methylation and transcriptome}

The original data obtained from WGBS and RNA-Seq were analyzed and compared. Differential gene functions were obtained from the soybean database. The intersections of DNA methylation levels and gene expression levels were taken for conjoint analysis, and the genes which were different in both analysis groups were screened. The criteria for selecting the intersection genes were $p$-value $<0.05$.

\section{MapMan biological function annotation}

The amino acid sequence of the unigene coding protein obtained by CDS analysis was submitted to the MapMan website application online software mercator (http://mapman.gabipd.org/web/guest/mercator) for annotation of the biological functions of the encoding protein. The mapping information of the biological processes of the species was obtained.

\section{Pyrosequencing PCR (PS-PCR) validation}

Five genes with negative correlations between DNA methylation and gene expression were randomly selected. DNA methylation validation was conducted using the PS-PCR method. The DMR regions corresponding to those five genes were identified, and Kismeth website (http://katahdin.mssm.edu/kismeth/primer_design.pl) was used for the online design of the nest PCR primer (Table S5).

\section{Validation of candidate DMGs by quantitative real-time PCR (qRT-PCR)}

The primer sequence was designed with Primer Premier 5.0 software (Premier Biosoft International, Palo Alto, CA) (Table S5). Next, $1.0 \mu \mathrm{g}$ of total RNA was reverse-transcribed by reverse transcriptase according to the protocol of iScript cDNA Synthesis Kit (Bio-Rad, CA, USA), and used as the template for the following qRT-PCR amplification. The qRT-PCR reaction mixture $(25.0 \mu \mathrm{L})$ contained SybrGreen qPCR Master Mix ( $2 \times$ concentration, Ruian Biotechnologies, Shanghai, China) $10.0 \mu \mathrm{L}$, upstream primer $0.6 \mu \mathrm{L}$, downstream primer $(10.0$ $\mu \mathrm{M}) 0.6 \mu \mathrm{L}$, cDNA $1.0 \mu \mathrm{L}$, and $\mathrm{ddH}_{2} \mathrm{O} 7.8 \mu \mathrm{L}$. The thermal cycling conditions were as follows: Pre-denaturation at $95{ }^{\circ} \mathrm{C}$ for $2 \mathrm{~m}$; followed by 40 cycles of heating at $95{ }^{\circ} \mathrm{C}$ for $10 \mathrm{~s}$ and annealing at $60{ }^{\circ} \mathrm{C}$ for $40 \mathrm{~s}$. $\beta$-actin gene was used as the internal control gene. The relative level of genes expression was evaluated by the $2^{-\Delta \Delta c t}$ method.

\section{Additional files}


Table S1 The negatively correlated genes between transcription and methylation of soybean resistance to bean pyralid larvae.

Table S2 Pathway analysis of the negatively correlated genes.

Table S3 Pathway analysis of the negatively correlated genes in the promoter regions.

Table S4 MapMan cluster analysis of the negatively correlated genes.

Table S5 Primers for the qRT-PCR and PS-PCR.

\section{Abbreviations}

WGBS: Whole-genome bisulfite sequencing; RNA-Seq: RNA-sequencing; DMG: Differentially methylated gene; DMR: Differentially methylated region; DMP: Differentially methylated promoter; DEG: Differentially expressed gene; GO: Gene Ontology; KEGG: Kyoto Encyclopedia of Genes and Genomes; PS-PCR: Pyrosequencing PCR; qRT-PCR: Quantitative real-time PCR; CRK: Cysteine-rich receptor-like protein kinase; STK: Serine/threonine protein kinase; CSC: Cellulose synthase complex; CesA: Cellulose synthase monomer; KIN: Kinesin; SBT: subtilisin-like protease; CYP: Cytochrome P450.

\section{Funding}

This work was supported by the grants from the Natural Science Fundation of Guangxi (2017GXNSFDA198037, 2016GXNSFAA380238), and the Development Foundation of Guangxi Academy of Agricultural Sciences (2020YM116, 2021YT054).

\section{Availability of data and materials}

All data were submitted to the National Center for Biotechnology Information (NCBI) under SRA number SRA549176.

\section{Author contributions}

ZS and WZ conceived and designed the experiments. WZ, RT, SL, ZS, ZL, SY, HC and XQ performed the experiments. WZ, RT and SL analyzed the data. ZS and WZ contributed reagents/materials/analysis tools. ZS and WZ conceived the experiments and wrote the manuscript. All authors read and approved the final manuscript.

\section{Ethics approval and consent to participate}

Not applicable for this research. Soybean seeds for this study were obtatined from the Guangxi Academy of Agricultual Scinence.

\section{Consent for publication}

Not applicable.

\section{Conflicts of interests}

The authors declare that they have no competing interests.

\section{References}

1. Editorial committee of plate of Chinese diseases and insects on crop. Plate of Chinese diseases and insects on crop, fifth fascicule, diseases and insects on Oil Crop (first). Beijing: Agricultural press. 1982, p.136-7.

2. Cui ZL, Gai JY, Ji DF, Ren ZJ. A study on leaf-feeding insect species on soybeans in Nanjing area. Soybean Sci. 1997, 16:12-20.

3. Sun ZD, Yang SZ, Chen HZ, Li CY, Long LP. Identification of soybean resistance to bean pyralid (Lamprosema indicata Fabricicus) and obiposition preference of bean pyralid on soybean varieties. Chin J Oil Crop Sci. 2005, 27(4): 69-71.

4. Xing GN, Zhou B, Wang YF, Zhao TJ, Yu DY, Chen SY, Gai JY. Genetic components and major QTL confer resistance to bean pyralid (Lamprosema indicata Fabricius) under multiple environments in four RIL populations 
of soybean. Theor Appl Genet. 2012, 125: 859-875.

5. Li GJ, Cheng LG, Zhang GZ, He XH, Zhi HJ, Zhang YM. Mixed major-gene plus polyegens inheritance analysis for resistance in soybean to bean pyralid (Lamprosema indicata Fabricius). Soybean Sci. 2008, 27(1): 33-36, 41 .

6. Li GJ, Li HN, Cheng LG, Zhang YM. Mapping quantitative traitloci for resistance in soybean to bean pyralid (Lamprosema indicata Fabricius) . Chin J Oil Crop Sci. 2009, 31(3): 365-369.

7. Zeng WY, Cai ZY, Zhang ZP, Chen HZ, Yang SZ, Tang XM, Lai ZG, Sun ZD. Physiological and biochemical characteristics of Lamprosema indicata (Fabricius)-resistant soybean. J Southern Agric. 2016, 46(12): 2112-2116. 8. Zeng WY, Sun ZD, Lai ZG, Cai ZY, Chen HZ, Yang SZ, Tang XM. Correlation analysis on transcriptomic and proteomic of soybean resistance to bean pyralid (Lamprosema indicata). Sci Agric Sin. 2018, 51(7): 1244-1260.

9. Zeng WY, Sun ZD, Cai ZY, Chen HZ, Lai ZG, Yang SZ, Tang XM. Proteomic analysis by iTRAQ-MRM of soybean resistance to Lamprosema indicate. BMC Genomics. 2017, 18: 444.

10. Zeng WY, Sun ZD, Cai ZY, Chen HZ, Lai ZG, Yang SZ, Tang XM. Comparative transcriptome analysis of soybean response to bean pyralid larvae. BMC Genomics. 2017, 18: 871.

11. Zeng WY, Sun ZD, Lai ZG, Yang SZ, Chen HZ, Yang XH, Tao JR, Tang XM. Determination of the MiRNAs related to bean pyralid larvae resistance in soybean using small RNA and transcriptome sequencing. Int J Mol Sci. 2019, 20: 2966.

12. Dowen RH, Pelizzola M, Schmitz RJ, Lister R, Dowen JM, Nery JR, Dixon JE, Ecker JR. Widespread dynamic DNA methylation in response to biotic stress. Proc Natl Acad Sci USA. 2012, 109: E2183-E2191.

13. Sha AH, Lin XH, Huang JB, Zhang DP. Analysis of DNA methylation related to rice adult plant resistance to bacterial blight based on methylation - sensitive AFLP (MSAP) analysis. Mol Genet Genomics. 2005, 273(6): 484-490.

14. Akimoto K, Katakami H, Kim HJ, Ogawa E, Sano H. Epigenetic inheritance in rice plants. Ann Bot (Lond). 2007, 100(2): 205-217.

15. Kovalchuk I, Kovalchuk O, Kalck V, Boyko V, Filkowski J, Heinlein M, Hohn B. Pathogen-induced systemic plant signal triggers DNA rearrangements. Nature. 2003, 423: 760-762.

16. Boyko A, Kathiria P, Zemp FJ, Yao YL. Transgenerational changes in the genome stability and methylation in pathogen-infected plants. Nucl Acids Res. 2007, 35(5): 1714-1725.

17. Rambani A, Rice JH, Liu JY, Lane T, Mazarei M, Pantalone V, Stewart CN, Staton M, Hewezi T. The methylome of soybean roots during the compatible interaction with the soybean Cyst Nematode. Plant Physiol. 2015, 168(4): 1364-1377.

18. Hewezi T, Lane T, Piya S, Rambani A, Rice JH, Staton M. Cyst Nematode parasitism induces dynamic changes in the root epigenome. Plant Physiol. 2017, 174(1): 405-420.

19. Wang WS, Pan YJ, Zhao XQ, Dwivedi D, Zhu LH, Fu BY, Li ZK. Drought-induced site-specific DNA methylation and its association with drought tolerance in rice (Oryza sativa L.). J Exp Bot. 2011, 62(6): 1951-1960.

20. Zhou SQ, Lou YR, Tzin V, Jander G. Alteration of plant primary metabolism in response to insect herbivory.

Plant Physiol. 2015, 169(3): 1488-1498.

21. Craig A, Ewan R, Mesmar J, Gudipati V, Sadanandom A. E3 ubiquitin ligases and plant innate immunity. J Exp Bot. 2009, 60(4): 1123-1132.

22. León J, Rojo E, Sánchez-Serrano J. Wound signaling in Plants. J Epx Bot. 2001, 52(354): 1-9.

23. Fan FF, Li FF, Li JQ, Zhan QW, Wang LH, Liu YL. Research progress of cinnamoyl-CoA reductase (CCR) gene in plants. China Biotech. 2015, 35(12): 96-102.

24. Figueiredo J, Marta SS. Subtilisin-like proteases in plant defence: the past, the present and beyond. Mol Plant Pathol. 2018, 19: 1017-1028. 
25. Schwachtje J, Baldwin IT. Why does herbivore attack reconfigure primary metabolism? Plant Physiol. 2008, 146: $845-851$.

26. Winkel-Shirley B. Biosynthesis of flavonoids and effects of stress. Curr Opin Plant Biol. 2002, 5(3): 218-223.

27. Nakashima K, Ito Y, Yamaguchi-Shinozaki K. Transcriptional regulatory networks in response to abiotic stresses in Arabidopsis and grasses. Plant Physiol. 2009, 149: 88-95.

28. Verma V, Ravindran P, Kumar PP. Plant hormone-mediated regulation of stress responses. BMC Plant Biol. 2016, 16: 86 .

29. Huot B, Yao J, Montgomery BL, He SY. Growth-defense tradeoffs in plants: a balancing act to optimize fitness. Mol Plant. 2014, 7(8): 1267-1287.

30. Chinnusamy V, Zhu JK. Epigenetic regulation of stress responses in plants. Curr Opin Plant Biol. 2009, 12(2): 133-139.

31. Gao DH, Gao X, Liu J, Kimatu JN. Methylation sensitive amplified polymorphism (MSAP) reveals that alkali stress triggers more DNA hypomethylation levels in cotton (Gossypium hirsutum L) roots than salt stress. African J Biotechnol. 2011, 10(82): 18971-18980.

32. Hsieh PH, He SB, Buttress T, Gao HB, Couchman M, Fischer RL, Zilberman D, Feng XQ. Arabidopsis male sexual lineage exhibits more robust maintenance of CG methylation than somatic tissues. Proc Natl Acad Sci USA. 2016, 113(52): 15132-15137.

33. Bewick AJ, Schmitz RJ. Gene body DNA methylation in plants. Curr Opin Plant Biol. 2017, 36: 103-110. 34. Song QX, Lu X, Li QT, Chen H, Hu XY, Ma B, Zhang WK. Genome-wide analysis of DNA methylation in soybean. Mol Plant. 2013, 6(6): 1961-1974.

35. Li YW, Ding XL, Wang X, He TT, Zhang H, Yang LS, Wang TL, Chen LF, Gai JY, Yang SP. Genome-wide comparative analysis of DNA methylation between soybean cytoplasmic male- sterile line NJCMS5A and its maintainer NJCMS5B. BMC Genomics. 2017, 18: 596.

36. Howe GA, Jander G. Plant immunity to insect herbivores. Annu Rev Plant Biol. 2008, 59: 41-66.

37. Bourdais G, Burdiak P, Gauthier A, Nitsch L, Salojärvi J, Rayapuram C, Idänheimo N, Hunter K, Kimura S, Merilo E, Aleksia V, Oracz K, Kaufholdt D. Large-scale phenomics identifies primary and fine-tuning roles for CRKs in responses related to oxidative stress. PLoS Genet. 2015, 11(7): e1005373.

38. Delgado-Cerrone L, Alvarez A, Mena E, León IPD, Montesano M. Genome wide analysis of the soybean CRK-family and transcriptional regulation by biotic stress signals triggering plant immunity. PLoS One. 2018, 13(11): e0207438.

39. Afzal AJ, Wood AJ, Lightfoot DA. Plant receptor-like serine threonine kinases: Roles in signaling and plant defense. Mol Plant-Microbe In. 2008, 21(5): 507-517.

40. Hasegawa PM, Bressan RA, Zhu JK, Bohnert HJ. Plant cellular and molecular responses to high salinity. Annu Rev Plant physiol Plant Mol Biol. 2000, 51: 463-499.

41. Zipfel C. Pattern-recognition receptors in plant innate immunity. Cum Opin Immunol. 2008, 20(1): 10-16.

42. Zhang J. Differential proteomic analysis of the Arabidopsis thaliana in response to insect feeding and mechanical wounding. Master's thesis of Jilin Agriculture University. 2011.

43. Fan R, Wang H, Wang YL, Yu DY. Proteomic analysis of soybean defense response induced by cotton worm (prodenia litura Fabricius) feeding. Proteome Sci. 2012, 10(5): 16-21.

44. Link VL, Hofmann MG, Sinha AK, Ehness R, Strnad M, Roitsch T. Biochemical evidence for the activation of distinct subsets of mitogen-activated protein kinases by voltage and defence-related stimuli. Plant Physiol. 2002, 128(1): 271-281.

45. Camps M, Nichols A, Arkinstall S. Dual specificity phosphatases: a gene family for control of MAP kinase function. Faseb J. 2000, 14(1): 6-16.

46. Wu JQ, Hettenhausen C, Meldau S, Baldwin IT. Herbivory rapidly activates MAPK signaling in attaeked and 
unattaeked leaf regions but not between leaves of Nicoliana attenuate. Plant Cell. 2007, 19(3): 1096-1122.

47. Heinrich M, Baldwin IT, Wu J. Two mitogen-activated protein kinase kinases, MKK1 and MEK2, are involvedin wounding and specialist lepidopteran herbivore Manduca sexta-induced responses in Nicotiana attenuata. J Exp Bot. 2011, 62: 4355-4365.

48. Heinrich M, Baldwin IT, Wu J. Three MAPK kinases, MEK1, SIPKK, and NPK2, are not involved in activation of SIPK after wounding and herbivore feeding but important for accumulation of trypsin proteinase inhibitors. Plant Mol Biol Rep. 2012, 30: 731-740.

49. Sözen C, Schenk ST, Boudsocq M, Chardin C. Wounding and insect feeding trigger two independent MAPK pathways with distinct regulation and kinetics. Plant Cell. 2020, 32: 1988-2003.

50. Brewin NJ, Kardailsky IV. Legume lectins and no-dulation by Rhizobium. Trends Plant Sci. 1997, 2: 92-98.

51. Brill LM, Evans CJ, Hirsch AM. Expression of MsLEC1- and MsLEC2-antisense genes in alfalfa plant lines causes severe embryogenic, developmental and reproductive abnormalities. Plant J. 2001, 25: 453-461.

52. Rüdiger H, Gabius HJ. Plant lectins: occurrence, biochemistry, functions and applications. Glycoconj J. 2001, 18: 589-613.

53. Gilardoni PA, Hettenhausen C, Baldwin IT, Bonaventure G. Nicotiana attenuata LECTIN RECEPTOR KINASE 1 suppresses the insect-mediated inhibition of induced defense responses during Manduca sexta herbivory. Plant Cell. 2011, 23: 3512-3532.

54. Bonaventure G. The Nicotiana attenuata lectin receptor kinase 1 is involved in the perception of insect feeding. Plant Signal Behav. 2011, 6: 2060-2063.

55. Liu YQ, Wu H, Chen H, Liu YL, He J, Kang HY, Sun ZG, Pan G, Wang Q, Hu JL, Zhou F, Zhou KN, Zheng XM, Ren YL, Chen LM, Wang YH, Zhao ZG, Lin QB, Wu FQ, Zhang X, Guo XP, Cheng XN, Jiang L, Wu CY, Wang HY, Wan JM. A gene cluster encoding lectin receptor kinases confers broad-spectrum and durable insect resistance in rice. Nat Biotechnol. 2015, 33: 301-305.

56. Keegstra K. Plant cell walls. Plant Physiol. 2010, 154(2): 483-486.

57. Houston K, Tucker MR, Chowdhury J, Shirley N, Little A. The plant cell wall: a complex and dynamic structure as revealed by the responses of genes under stress conditions. Front Plant Sci. 2016, 7: 228.

58. Tenhaken R. Cell wall remodeling under abiotic stress. Front Plant Sci. 2015, 5: 771.

59. McFarlane HE, Dring A, Persson S. The cell biology of cellulose synthesis. Annu Rev Plant Biol. 2014, 65: 69-94.

60. Carroll A, Somerville C. Cellulosic biofuels. Annu Rev Plant Biol. 2009, 60: 165-182.

61. Crowell EF, Bischoff V, Desprez T, Desprez T, Rolland A, Stierhof YD, Schumacher K, Gonneau M, Höfte H, Vernhettes S. Pausing of Golgi bodies on microtubules regulates secretion of cellulose synthase complexes in Arabidopsis. Plant Cell. 2009, 21(4): 1141-1154.

62. Gutierrez R, Lindeboom JJ, Paredez AR, Emons AMC. Arabidopsis cortical microtubules position cellulose synthase delivery to the plasma membrane and interact with cellulose synthase trafficking compartments. Nat Cell Biol. 2009, 11(7): 797-806.

63. Liu TM, Zhu SY, Tang QM. De novo assembly and characterization of transcriptome using illumian paired-end sequencing and identification of CesA gene in ramie (Boehmeria nivea L. Gaud). BMC Genomics. 2013, 14: 125.

64. Lei L, Singh A, Bashline L, Li S, Yingling YG, Gu Y. CELlULOSE SYNTHASE INTERACTIVE1 is required for fast recycling of cellulose synthase complexes to the plasma membrane in Arabidopsis. Plant Cell. 2015, 27 (10): 2926-2940.

65. Zhu XY, Li SD, Pan SQ, Xin XR, Gu Y. CSI1, PATROL1, and exocyst complex cooperate in delivery of cellulose synthase complexes to the plasma membrane. Proc Natl Acad Sci USA. 2018, 115 (15): E3578-E3587.

66. Li SD, Lei L, Somerville CR, Gu Y. Cellulose synthase interactive protein1 (CSI1) links microtubules and 
cellulose synthase complexes. Proc Natl Acad Sci USA. 2012, 109(1): 185-190.

67. Karpova TS, Tatchell K, Cooper JA. Actin filaments in yeast are unstable in the absence of capping protein or fimbrin. J Cell Biol. 1995, 131: 1483-1493.

68. Zhong R, Burk DH, Morrison WH, Ye ZH. A kinesin-like protein is essential for oriented deposition of cellulose microfibrils and cell wall strength. Plant Cell. 2002, 14: 3101-3117.

69. Zhu C and Dixit R. Single molecule analysis of the Arabidopsis FRA1 kinesin shows that it is a functional motor protein with unusually high processivity. Mol Plant, 2011, 4(5): 879-885.

70. Kong ZS, Ioki M, Braybrook S, Li SD, Ye ZH, Julie Lee YRJ, Hotta T, Chang A, Tian J, Wang GD, Liu B. Kinesin-4 functions in vesicular transport on cortical microtubules and regulates cell wall mechanics during cell elongation in plants. Mol Plant. 2015, 8(7): 1011-1023.

71. Ambrose C, Allard JF, Cytrynbaum EN, Wasteneys GO. A CLASP-modulated cell edge barrier mechanism drives cell-wide cortical microtubule organization in Arabidopsis. Nat Commun. 2011, 2: 430.

72. Lindeboom JJ, Nakamura M, Saltini M, Hibbel A, Walia A, Ketelaar T, Emons AMC, Sedbrook J, Kirik V, Mulde BM, Ehrhardt DW. CLASP stabilizes microtubule plus ends created by serving to drive cortical array reorientation. J Cell Biol. 2018, 218(1): 190-205.

73. Shen ZJ. Mechanism of herbivorous insect resistance and salt tolerance in mangrove plant Avicennia marina. Doctoral Dissertation of Xiamen University. 2018.

74. Harvey PJ, Campanella BF, Castro PML, Harms H, Lichtfouse E, Schoffner AR, Smrcek S, Werck-Reichhart D. Phytoremedition of polyaromatic hydrocarbons, anilines and phenols. Envi Sci Pollut Res. 2002, 9(1): 29-47.

75. Schuler MA, Daniele WR. Functional genomics of P450s. Annu Rev Plant Biol. 2003, 54(1): 627-629.

76. Morant M, Bak S, Moller BL, Werck-Reichhart D. Plant cytochromes P450: tools for pharmacology, plant protection and phytoremediation. Curr Opin Biotech. 2003, 14(2): 151-162.

77. Kahn RA, Bak S, Svendsen J, Halkier B A, Moller BL. Isolation and reconstitution of cytochrome P450ox and in vitro reconstitution of the entire biosynthetic pathway of the cyanogenic glucoside dhurrin from sorghum. Plant Physiol. 1997, 115(4): 1661-1670.

78. Lu HP, Luo T, Fu HW, Wang L, Tan YY, Huang JZ, Wang Q, Ye GY, Angharad MRG, Lou YG, Shu QY. Resistance of rice to insect pests mediated by suppression of serotonin biosynthesis. Nat Plants. 2018, 4: 338-344.

79. Gibbs DJ, Conde JV, Berckhan S, Prasad G, Mendiondo GM, Holdsworth MJ. Group VII ethylene response factors coordinate oxygen and nitric oxide signal transduction and stress responses in plants. Plant Physiol. 2015, 69: 23-31.

80. Erb M, Reymond P. Molecular interactions between plants and insect herbivores. Annu Rev Plant Biol. 2019, 70 (1): 527-557.

81. Li JJ, Guo X, Zhang MH, Wang X, Zhao Y, Yin ZG, Zhang ZY, Wang YM, Xiong HY, Zhang HL, Todorovska E, Li ZC. OsERF71 confers drought tolerance via modulating ABA signaling and proline biosynthesis. Plant Sci. 2018, 270: 131-139.

82. Takafuji K, Rim H, Kawauchi K, Mujiono K, Shimokawa S, Ando Y, Shiojiri K, Galis I, Arimura G. Evidence that ERF transcriptional regulators serve as possible key molecules for natural variation in defense against herbivores in tall goldenrod. Scientific Reports. 2020, 10(1): 5352.

83. Wu J, Gao H, Zhu XW, Li DF. An ERF transcription factor enhances plant resistance to Myzus persicae and Spodoptera litura. Biotechnol Biotec Eq. 2020, 34(1): 946-954.

84. Liu WW, Tai HH, Li SS, Gao W, Zhao M, Xie CX, Li WX. bHLH122 is important for drought and osmotic stress resistance in Arabidopsis and in the repression of ABA catabolism. New Phytol. 2014, 201(4): 1192-1204. 85. Friedrichsen DM, Nemhauser J, Muramitsu T, Maloof NJ, Alonso J. Three redundant brassinosteroid early response genes encode putative bHLH transcription factors required for normal growth. Genetics. 2002, 162(3): $1445-1456$. 
86. Zhang CJ, Hou YQ, Hao QN, Chen HF, Chen LM, Yuan SL, Shan ZH, Zhang XJ, Yang ZL, Qiu DZ, Zhou XN, Huang WJ. Genome-wide survey of the soybean GATA transcription factor gene family and expression analysis under low nitrogen stress. PLoS One. 2015, 10(4): e0125174.

87. Lister R, Pelizzola M, Dowen RH, Hawkins RD, Hon G, Tonti-Filippini J, Nery JR, Lee L, Ye Z, Ngo Q, Edsall L, Antosiewicz-Bourget J, Stewart R, Ruotti V, Millar AH, Thomson JA, Ren B, Ecker JR. Human DNA methylomes at base reolution show widespread epigeomic differences. Nature. 2009, 462(7271): 315-322. 88. Heyn H, Li N, Ferreira HJ, Moran S, Pisano DG, Gomez A. Distinct DNA methylomes of newborns and centenarians. Proc Natl Acad Sci USA. 2012, 109(26): 10522-10527.

89. Kanehisa M, Goto S, Sato Y, Furumichi M, Tanabe M. KEGG for integration and interpretation of large-scale molecular data sets. Nucleic Acids Res. 2012, 40: 109-114.

Table 1 Summary of WGBS data

\begin{tabular}{|c|c|c|c|c|c|c|c|c|c|}
\hline Sample & Q20 Rate & Clean Reads & Clean & Mapping & Uniquely Mapping & Bisulfite Conversion & Duplication & Average & $1 \times$ Reads \\
\hline ID & $(\%)$ & Number & Rate (\%) & Rate (\%) & Rate $(\%)$ & Rate $(\%)$ & Rate $(\%)$ & Depth $(\times)$ & Coverage $(\%)$ \\
\hline HRK0 & 98.00 & $266,666,670$ & 93.61 & 89.57 & 75.23 & 99.60 & 16.21 & 25.45 & 93.61 \\
\hline HRK48 & 97.99 & $266,666,668$ & 93.21 & 89.92 & 74.59 & 99.58 & 16.16 & 25.22 & 93.43 \\
\hline HSK0 & 98.14 & $266,666,670$ & 87.64 & 92.09 & 76.98 & 99.61 & 15.42 & 26.28 & 93.54 \\
\hline HSK48 & 98.30 & $266,666,668$ & 88.29 & 90.50 & 75.76 & 99.58 & 17.14 & 25.30 & 93.61 \\
\hline
\end{tabular}

Note: HRK represented the highly resistant marterial Gantai-2-2; HSK represented the highly susceptible marterial

Wan82-178; and the numbers 0 and 48 represented the processing times.

Table 2 The average methylation level of methylation and some elements in different contexts

\begin{tabular}{llllllllll}
\hline Context & Sample & $\begin{array}{l}\text { Average Level } \\
\text { of Methylation (\%) }\end{array}$ & CDS (\%) & Down2k (\%) & Up2k (\%) & Exon (\%) & mRNA (\%) & $\begin{array}{l}\text { Repeat } \\
(\%)\end{array}$ & $\begin{array}{l}\text { CpG-island } \\
(\%)\end{array}$ \\
\hline C & HRK0 & 19.84 & 5.207 & 10.132 & 11.062 & 5.299 & 7.303 & 25.815 & 28.597 \\
& HRK48 & 21.30 & 5.441 & 11.182 & 12.218 & 5.607 & 7.965 & 27.090 & 28.950 \\
& HSK0 & 20.96 & 5.563 & 11.249 & 12.378 & 5.677 & 8.019 & 26.182 & 28.698 \\
& HSK48 & 18.37 & 5.156 & 8.924 & 9.688 & 5.100 & 7.008 & 25.396 & 26.625 \\
CG & HRK0 & 72.36 & 18.791 & 36.162 & 36.711 & 17.625 & 33.092 & 94.113 & 62.019 \\
& HRK48 & 73.33 & 18.121 & 37.534 & 38.155 & 17.301 & 33.034 & 94.326 & 61.385 \\
& HSK0 & 74.71 & 19.587 & 39.442 & 40.439 & 18.570 & 34.679 & 94.593 & 62.283 \\
& HSK48 & 68.27 & 19.732 & 31.538 & 31.641 & 17.581 & 32.772 & 93.837 & 57.562 \\
CHG & HRK0 & 46.14 & 7.715 & 25.111 & 28.541 & 9.231 & 12.804 & 70.380 & 48.399 \\
& HRK48 & 47.64 & 8.012 & 26.576 & 30.084 & 9.579 & 13.621 & 70.935 & 48.132 \\
& HSK0 & 47.40 & 8.127 & 27.020 & 31.062 & 9.665 & 13.959 & 69.872 & 47.921 \\
& HSK48 & 42.15 & 7.190 & 21.644 & 24.666 & 8.485 & 11.970 & 68.763 & 43.650 \\
& HRK0 & 4.90 & 1.318 & 3.008 & 3.525 & 1.460 & 1.942 & 6.923 & 6.062 \\
& HRK48 & 5.81 & 1.524 & 3.587 & 4.201 & 1.696 & 2.353 & 8.063 & 6.968 \\
& HSK0 & 5.08 & 1.364 & 3.154 & 3.686 & 1.511 & 2.064 & 6.939 & 6.056 \\
& HSK48 & 5.29 & 1.427 & 2.961 & 3.406 & 1.567 & 2.097 & 7.897 & 6.582 \\
\hline
\end{tabular}

Table 3 Proportion of CG, CHG and CHH in all methyl-cytosine

\begin{tabular}{lllll}
\hline Sample & & mCG & mCHG & mCHH \\
\hline HRK0 & mC number & $17,487,188$ & $16,644,623$ & $14,228,044$ \\
& Proportion (\%) & 36.16 & 34.42 & 29.42 \\
HRK48 & mC number & $17,244,372$ & $16,403,662$ & $16,368,103$ \\
& Proportion (\%) & 34.47 & 32.80 & 32.73 \\
HSK0 & mC number & $17,509,047$ & $16,554,658$ & $14,308,471$ \\
& Proportion (\%) & 36.20 & 34.22 & 29.58 \\
HSK48 & mC number & $17,606,421$ & $16,649,935$ & $16,413,930$ \\
& Proportion (\%) & 34.78 & 32.86 & 32.39 \\
\hline
\end{tabular}

Table 4 Pathway analysis of the DMGs

\begin{tabular}{llllll}
\hline Sample & Site & Pathway & DMGs with Pathway Annotation & $p$-value & Pathway ID
\end{tabular}




\begin{tabular}{|c|c|c|c|c|c|}
\hline \multirow[t]{2}{*}{ HRK0/HRK48 } & CG & Fructose and mannose metabolism & $3(1.99 \%)$ & 0.04756201 & ko00051 \\
\hline & CHG & Terpenoid backbone biosynthesis & $6(2.32 \%)$ & 0.003661496 & ko00900 \\
\hline \multirow[t]{11}{*}{ HSK0/HSK48 } & CG & Basal transcription factors & $9(1.34 \%)$ & 0.001368397 & ko03022 \\
\hline & & Fatty acid metabolism & $9(1.34 \%)$ & 0.0047815 & ko01212 \\
\hline & & Fatty acid biosynthesis & $6(0.89 \%)$ & 0.01282847 & ko00061 \\
\hline & & Propanoate metabolism & $6(0.89 \%)$ & 0.01282847 & ko00061 \\
\hline & & Taurine and hypotaurine metabolism & $3(0.45 \%)$ & 0.0241165 & ko00430 \\
\hline & & Thiamine metabolism & $4(0.60 \%)$ & 0.02645737 & ko00730 \\
\hline & & Vitamin B6 metabolism & $5(0.75 \%)$ & 0.04115753 & ko00750 \\
\hline & & Lysine degradation & $8(1.19 \%)$ & 0.04184757 & ko00310 \\
\hline & CHG & Thiamine metabolism & $5(0.75 \%)$ & 0.005305703 & ko00730 \\
\hline & & Non-homologous end-joining & $2(0.30 \%)$ & 0.01649522 & ko03450 \\
\hline & & mRNA surveillance pathway & $23(3.45 \%)$ & 0.03234759 & ko03015 \\
\hline \multirow[t]{21}{*}{ HSK0/HRK0 } & CG & Proteasome & $62(0.90 \%)$ & $3.446782 \mathrm{e}-07$ & ko03050 \\
\hline & & Porphyrin and chlorophyll metabolism & $39(0.56 \%)$ & 0.0003851172 & ko00860 \\
\hline & & Arginine biosynthesis & $30(0.43 \%)$ & 0.0005153445 & ko00220 \\
\hline & & Other types of O-glycan biosynthesis & $28(0.40 \%)$ & 0.0005550764 & ko00514 \\
\hline & & Inositol phosphate metabolism & $67(0.97 \%)$ & 0.001972833 & ko00562 \\
\hline & & Butanoate metabolism & $24(0.35 \%)$ & 0.005140221 & ko03040 \\
\hline & & Spliceosome & $181(2.61 \%)$ & 0.005140221 & ko03040 \\
\hline & & Purine metabolism & $76(1.10 \%)$ & 0.006294239 & ko00230 \\
\hline & & Non-homologous end-joining & $6(0.09 \%)$ & 0.009701395 & ko03450 \\
\hline & & Phosphatidylinositol signaling system & $62(0.90 \%)$ & 0.01495655 & ko04070 \\
\hline & & 2-Oxocarboxylic acid metabolism & $50(0.72 \%)$ & 0.01933169 & ko01210 \\
\hline & & Fructose and mannose metabolism & $49(0.71 \%)$ & 0.02097422 & ko00051 \\
\hline & & Fatty acid metabolism & $43(0.62 \%)$ & 0.03164016 & ko01212 \\
\hline & & Propanoate metabolism & $24(0.35 \%)$ & 0.03299536 & ko00640 \\
\hline & & Glycosphingolipid biosynthesis-lacto and neolacto series & $3(0.04 \%)$ & 0.03962215 & ko00601 \\
\hline & & Lysine biosynthesis & $14(0.20 \%)$ & 0.04167333 & ko00300 \\
\hline & CHG & Arginine biosynthesis & $10(0.52 \%)$ & 0.01543515 & ko00220 \\
\hline & & Histidine metabolism & $7(0.37 \%)$ & 0.02595471 & ko00340 \\
\hline & & Benzoxazinoid biosynthesis & $4(0.21 \%)$ & 0.02953415 & ko00402 \\
\hline & & Oxidative phosphorylation & $25(1.31 \%)$ & 0.04560989 & ko00190 \\
\hline & & Protein export & $11(0.58 \%)$ & 0.04978774 & ko03060 \\
\hline \multirow[t]{13}{*}{ HSK48/HRK48 } & CG & Proteasome & $54(0.79 \%)$ & 0.0001072989 & ko03050 \\
\hline & & Spliceosome & $189(2.76 \%)$ & 0.0003355189 & ko03040 \\
\hline & & Other types of O-glycan biosynthesis & $28(0.41 \%)$ & 0.0004669705 & ko00514 \\
\hline & & Butanoate metabolism & $25(0.36 \%)$ & 0.001468033 & ko00650 \\
\hline & & Porphyrin and chlorophyll metabolism & $36(0.53 \%)$ & 0.002476425 & ko00860 \\
\hline & & Arginine biosynthesis & $26(0.38 \%)$ & 0.008701094 & ko00220 \\
\hline & & Non-homologous end-joining & $6(0.09 \%)$ & 0.009208922 & ko03450 \\
\hline & & Inositol phosphate metabolism & $62(0.90 \%)$ & 0.01307215 & ko00562 \\
\hline & & One carbon pool by folate & $16(0.23 \%)$ & 0.01390304 & ko00670 \\
\hline & & Fatty acid metabolism & $44(0.64 \%)$ & 0.01762924 & ko01212 \\
\hline & & 2-Oxocarboxylic acid metabolism & $48(0.70 \%)$ & 0.03560632 & ko01210 \\
\hline & CHG & Phosphatidylinositol signaling system & $20(1.03 \%)$ & 0.04792616 & ko04070 \\
\hline & & Inositol phosphate metabolism & $20(1.03 \%)$ & 0.04942088 & ko00562 \\
\hline
\end{tabular}

Fig. 1 Canonical DNA methylation profiles of the entire transcriptional units

Fig. 2 Distribution of methylation level of $\mathrm{mC}$ in each sequence context

Fig. 3 Venn diagram of the differentially genes for the DNA methylation and transcriptome association analysis

Fig. 3-A HRK48/HRK0 in the gene body region

Fig. 3-B HSK48/HSK0 in the gene body region

Fig. 3-C HRK0/HSK0 in the gene body region

Fig.3-D HRK48/HSK48 in the gene body region

Fig. 3-E HRK48/HRK0 in the promoter region

Fig. 3-F HSK48/HSK0 in the promoter region 
Fig. 3-G HRK0/HSK0 in the promoter region

Fig. 3-H HRK48/HSK48 in the promoter region

Fig. 4 Expression levels of five DMGs validated by PS-PCR and qRT-PCR

Fig. 4-A Differently methylated levels in the HRK0/HSK0 and HRK48/HSK48

Fig. 4-B qRT-PCR analysis of the genes in the HRK0/HSK0 and HRK48/HSK48 
Figures
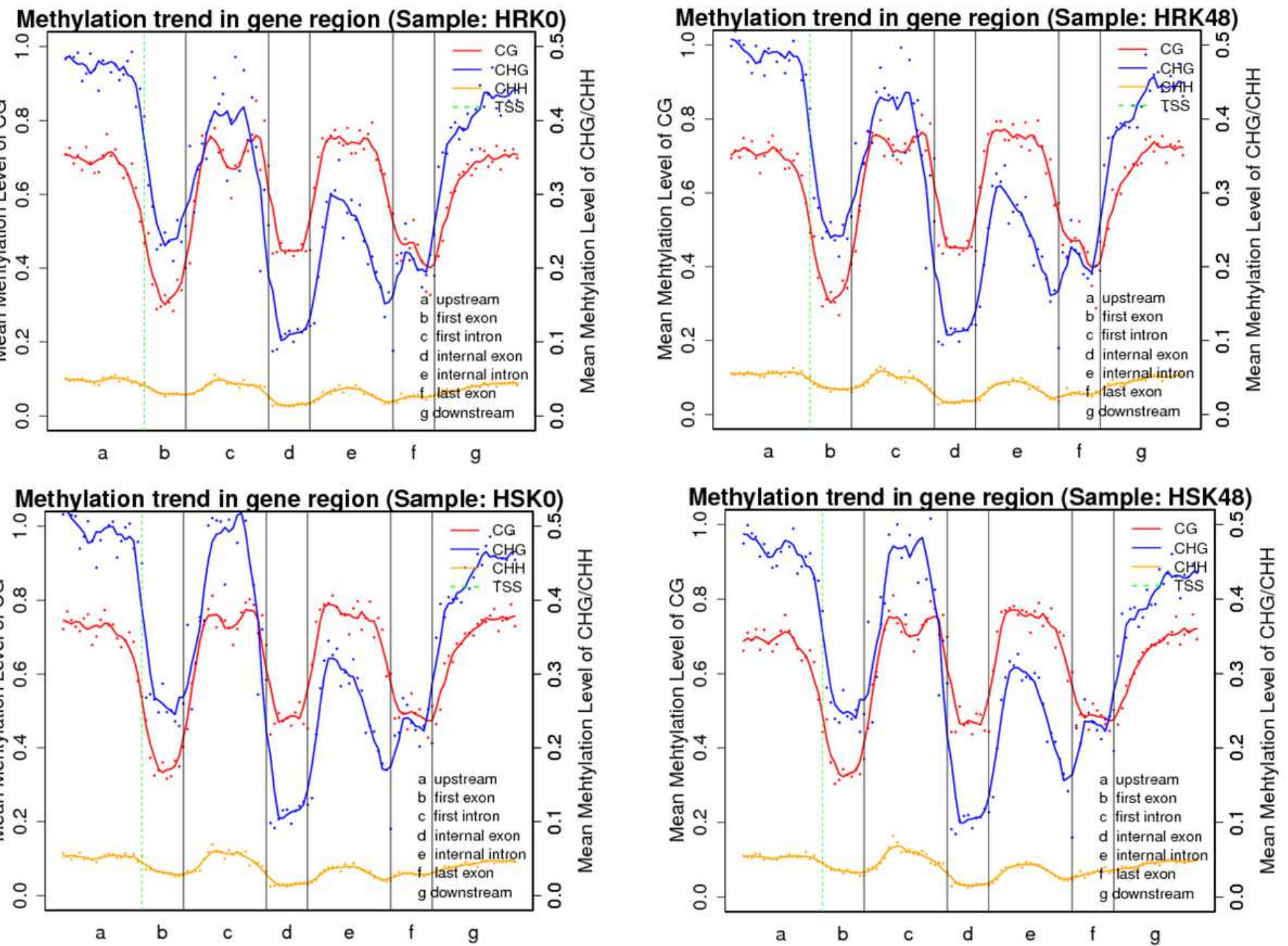

Figure 1

Canonical DNA methylation profiles of the entire transcriptional units 

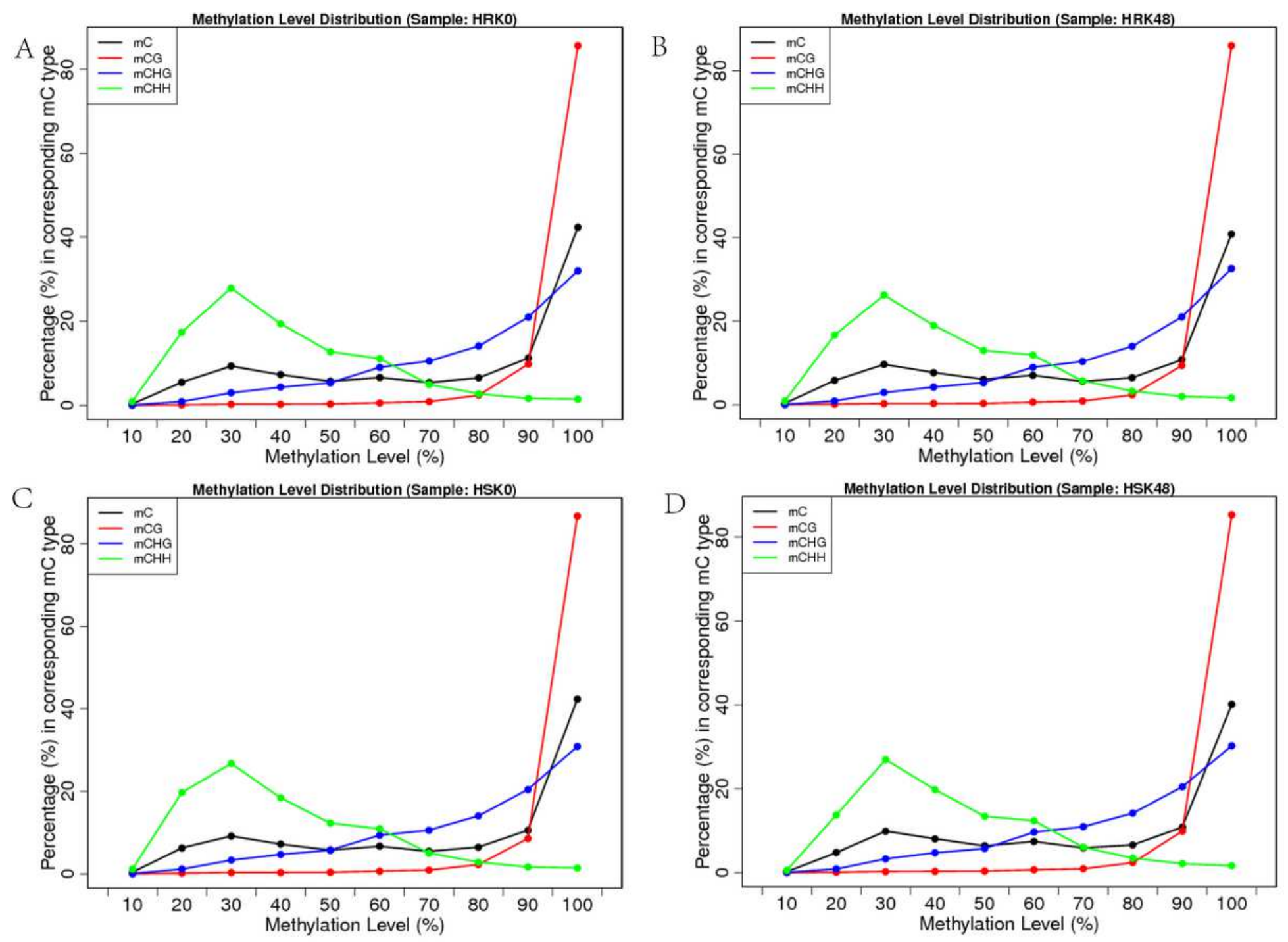

Figure 2

Distribution of methylation level of $\mathrm{mC}$ in each sequence context 

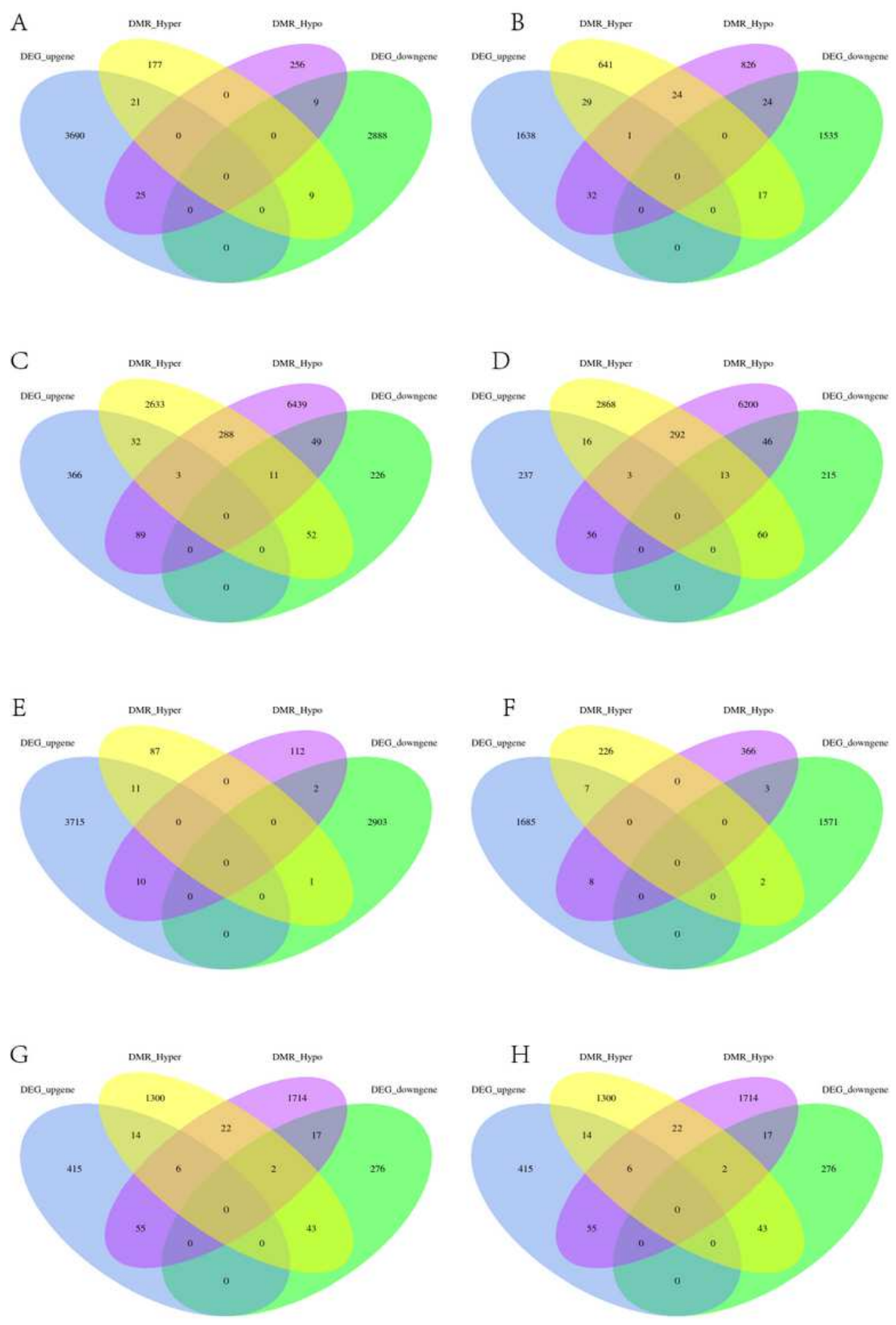

\section{Figure 3}

Venn diagram of the di fferential ly genes for the DNA methylation and transcriptome association analysis A HRK48/HRKO in the gene body region B HSK48/HSKO in the gene body region C HRKO/HSKO in the gene body region D HRK48/HSK48 in the gene body regio $n \mathrm{E} H \mathrm{HRK48/HRKO}$ in the promoter region F HSK48/HSKO in the promoter region G HRK0/HSKOG HRKO/HSKO in the promoter regionin the promoter region H HRK48/HSK48H HRK48/HSK48 in the promoter regionin the promoter region 

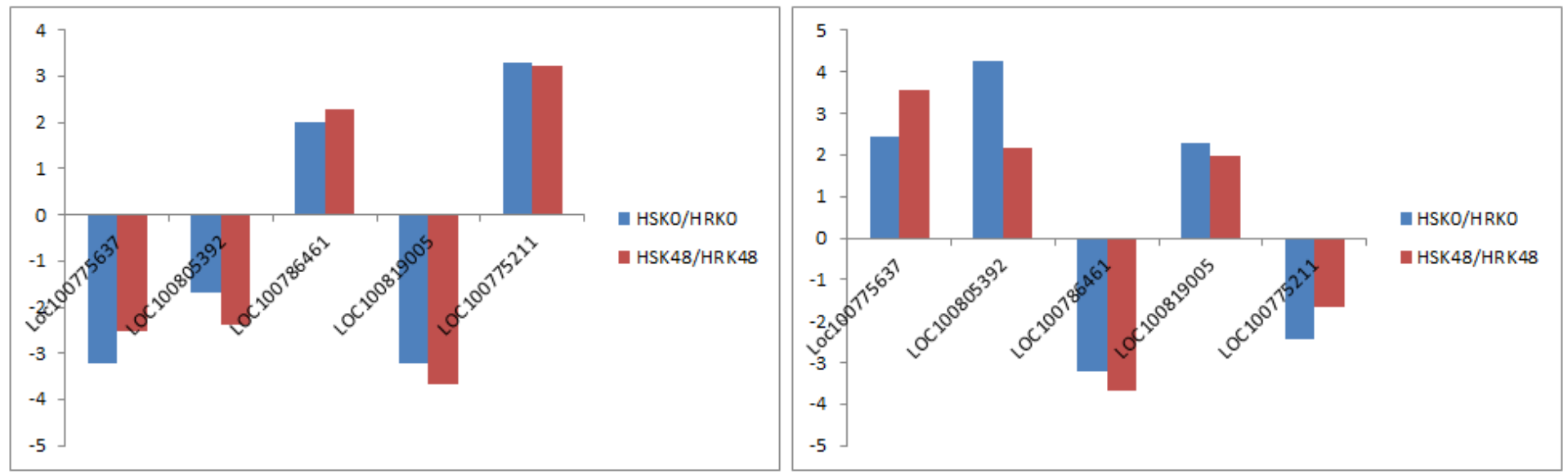

Figure 4

Expression level s of five DMGs validated by P S PCR and qRT PCR A Differently methylated levels in the HRKO/HSKO and HRK48/HSK48 B qRT PCR analysis of the genes in the HRKO/HSKO and HRK48/HSK48

\section{Supplementary Files}

This is a list of supplementary files associated with this preprint. Click to download.

- TableS1.Thenegativelycorrelatedgenesbetweentranscriptionandmethylationofsoybeanresistancetobeanpyralidlarvae.xlsx

- Tables2.Pathwayanalysisofthenegativelycorrelatedgenes.xlsx

- TableS3.Pathwayanalysisofthenegativelycorrelatedgenesinthepromoterregions.xlsx

- Tables4.MapManclusteranalysisofnegativelycorrelatedgenes.xlsx 